RESEARCH ARTICLE

\title{
Assessment of Physiological, Biochemical and Yield Attributes of Rice Cultivars under Elevated Ozone Stress
}

\author{
Periyasamy, Ambikapathi Ramya, Maheswari M , Jayabalakrishnan R.M., Saraswathi R and \\ Chandrasekhar C.N. \\ Department of Environmental Sciences, Tamil Nadu Agricultural University, Coimbatore, Tamil Nadu - 641003
}

\begin{abstract}
The present study aimed to assess the response of 15 rice cultivars exposed to elevated ozone stress. The plants were exposed to 100 ppb ozone (10:00$17: 00 \mathrm{~h}$ ) for 30 days at the reproductive stage. Elevated ozone significantly alters the physiological, biochemical, growth and yield traits of all test rice cultivars. Elevated ozone exposure significantly decreased photosynthetic rate maximally in MDU5 (42.90\%) and TRY(R)2 showed maximum reduction in stomatal conductance (42.39\%) and chlorophyll content (41.22\%). In terms of yield traits, a decrease in tiller number, number of effective tillers, number of filled spikelets per panicle and 1000 grain weight over the control were also observed. The multivariate analysis with a total variance of $58.86 \%$ categorized the 15 rice cultivars into ozone sensitive (TRY(R) 2, ASD16, ADT(R)45 and MDU5), moderately ozone sensitive (ASD18, ADT43, Rice MDU6, ADT36 and ADT37), moderately ozone tolerant (ADT(R)48 C047 and Rice C051) and ozone tolerant (Rice TPS5, Anna(R)4 and PMK(R)3) under $100 \mathrm{ppb}$ ozone. The present results revealed that the ozone tolerant rice cultivars would be recommended to cultivate in the regions experiencing high ozone concentration.
\end{abstract}

Keywords: Rice cultivars; Elevated ozone; Plant traits; Principle Component Analysis.

\section{INTRODUCTION}

Tropospheric ozone pollution is considered as an important threat to crop species and food security. In the current scenario, tropospheric ozone and precursors are increasing due to industrialization and urbanization. In southern parts of India, ozone concentrations were varied from $<10$ to $>200 \mathrm{ppb}$. According to Pulikesi et al.(2006), ozone concentrations ranged from 30 to $69 \mathrm{ppb}$ during March to October, 2005 at Chennai. The ozone concentrations were recorded as 29-67 ppb (December - July, 2009) in Anantapur (Reddy et al., 2010), 19.04-50.83 ppb (summer, 2012) in Suchindrum, Tamil Nadu (Sharma et al., 2013), 16.8 - 101.2 ppb (Summer, 2016) in chennai, Tamil Nadu (Prabakaran et al., 2017) and 1.11 - 292.36 ppb (pre monsoon,2016) in chennai, Tamil Nadu (Mohan and Saranya, 2019).

Some projections articulate that ozone was projected to rise at a rate of $10 \mathrm{ppb}$ per decade from 2000 to 2020 (Austin and Butchart, 2003). As per the projection, a $40 \%$ increase in 03 concentration is expected in the South Asian region by the year 2050 (Tai et al., 2014). Simulations for the period 2050 project boosts in the ozone of 20 to 25 per cent and simulations through 2100 indicate that ozone may increase by 40 to 60 per cent (Hauglustaine et al., 2005). Impacts are going to be most severe over many parts of India and China in recent decades (Lal et al., 2017).

Ozone incidents on the crop can be both chronic exposure (high background ozone concentration throughout the growing season) as well as acute ozone stress when concentrations exceed approximately 100 parts per billion (ppb), which can lead to the hypersensitive response and stimulation of cell death (Osborne, 2016). The global threat to food security due to ground level 03 pollution and its interaction with climate change scenario has been well documented by many researchers (Sarkar et al., 2015, Van Dingenen et al., 2009; Avnery et al., 27 2013).

Rice is known to be as susceptible to tropospheric ozone pollution as other major crop species like soybean and wheat (Biswas et al., 2008; Sinha et al., 2015; Daripa et al., 2016), particularly cultivars from the Asian region (Shi et al., 2009; Wang et al., 2012; Ramya et al., 2020). During the 1990's, there were five global hot spots where three months mean tropospheric ozone reached 60-70 ppb and 
two of the hot spots were in most of the rice growing regions of China and India (Emberson et al., 2009). The global crop yield loss due to tropospheric ozone was estimated to be worth \$14-26 billion for the year 2000 , about $40 \%$ of which may be occurring in China and India (Van Dingenen et al., 2009). Ozoneinduced damage to rice in India is estimated to be $2.1 \pm 0.8 \mathrm{Mt}$ which was sufficient to feed roughly 35 per cent of the population in India (Ghude et al., 2014). Furthermore, in India, annual loss of 0.3-6.7 million ton (0.3-6.3\%) for rice crop is estimated based on the accumulated ozone over a threshold of $40 \mathrm{ppb}$ (AOT40) and mean ozone for 7 h during the day (M7) (Lal et al., 2017). Hence, the present investigation is concentrated on assessing the response physiological, biochemical and yield traits of rice cultivars under elevated ozone stress.

\section{MATERIAL AND METHODS}

Fifteen short duration rice cultivars i.e., i) Rice $C O$ 51,ii)C0 47, iii)ADT36, iv)ADT37, v)ADT43, vi)ADT(R) 45, vii) ADT(R) 48, viii)ASD 16, ix)ASD 18, x) MDU 5, xi) MDU 6, xii) Rice TPS 5, xiii) TRY 2, xiv) Rice Anna 4 and $x v)$ Rice $P M K(R) 3$, which are widely cultivated by farmersaroundTamilNaduregion(Table1)weretaken for assessing the impact of elevated tropospheric ozone (100 ppb from 10:00 to 17:00 h) exposure for 30 days from 51 DAS to 80 DAS. The exposure index for ozone concentration, i.e., AOT 40 (accumulated hourly ozone concentration above $40 \mathrm{ppb}$ ), was calculated by the formula explained by Mauzeralland Wang (2001),

$$
\text { AOT40 }=\sum_{\square=1}^{\square} \square_{3}-40
$$

where, $\mathrm{O}_{3}$ denotes the mean ozone values per hour (ppb) which is above $40 \mathrm{ppb}$, i is the index, and $\mathrm{n}$ indicates the number ofhours.

The physiological parameters i.e., photosynthetic rate, stomatal conductance and chlorophyll content, the biochemical parameters i.e., proline and malondialdehyde, ascorbic acid content, the growth parameters i.e., root length, shoot length, tiller number and the yield parameters i.e., panicle length, number of effective tillers per plant, number of spikelets per panicle, number of filled spikelets per panicle, 1000 grain weight and straw weight per plant were taken for analysis.

Photosynthetic rate and stomatal conductance were quantified using a portable photosynthesis system (ADC BioScientific LCpro-SD System, UK) and chlorophyll content was measured using a chlorophyll content meter (CCM-200+, USA). The malondialdehyde content (MDA) was estimated by following the protocol of Heath and Pacber (1968) and expressed as $\mu \mathrm{mol} g-1$ fresh weight. The proline content was carried out according to the method of Bates et al. (1973) and expressed as $\mu \mathrm{mol} \mathrm{g}^{-1}$ fresh weight. Ascorbic acid content (AsA) was measured by using 2, 6 dichlorophenol indophenol (DCPIP) reduction method (Keller and Schwager, 1977) and expressedas mgg-1 fresh weight. All the physiological and biochemical traits were observed after 30 days of 100 ppbozoneexposure. Allthegrowthandyield traits were measured at the crop maturity stage.

\section{Statistical analysis}

The relative plant physiological, biochemical and yield traits were calculated using the following formula, Relative plant trait $=($ ozone $/$ control $) \times 100$. All the plant traits were displayed as relative plant traits. All the statistical analyses were performed using the SPSS tool (SPSS Inc., version 16.0.0). P-value less than $0.05(P<0.05)$ considered as significant. The multivariate analysis (Principal component analysis) was performed using $\mathrm{R}$ software (Version 3.5.1) and OriginPro 2019 (version 9.6.5) was used to plot the graphs.

\section{RESULTS AND DISCUSSION}

\section{Ozone exposure}

A report by number of researchers indicated that AOT40 for rice growing season at various sites of India exceeding the threshold level. The AOT40 values of $11.2 \mathrm{ppm}$.h at Varanasi for the period July to September, 2011 were showed significant yield loss in rice cultivars (Sarkar et al., 2015). Similarly, at Mohali AOT40 recorded as 19.8 and 12.6 ppm.h from June to Septembe r, 2012 and 2013, respectively registered growth and yield loss in rice cultivars (Sinha et al., 2015). Kumari et al., (2020) reported that AOT40 of 1.9 and $2.4 \mathrm{ppm}$.h were recorded from July to September, 2010 and 2015, respectively. In present study, the calculated AOT40 was recorded as 10.3 ppm.h showed significant reduction in physiological, growth and yield traits.

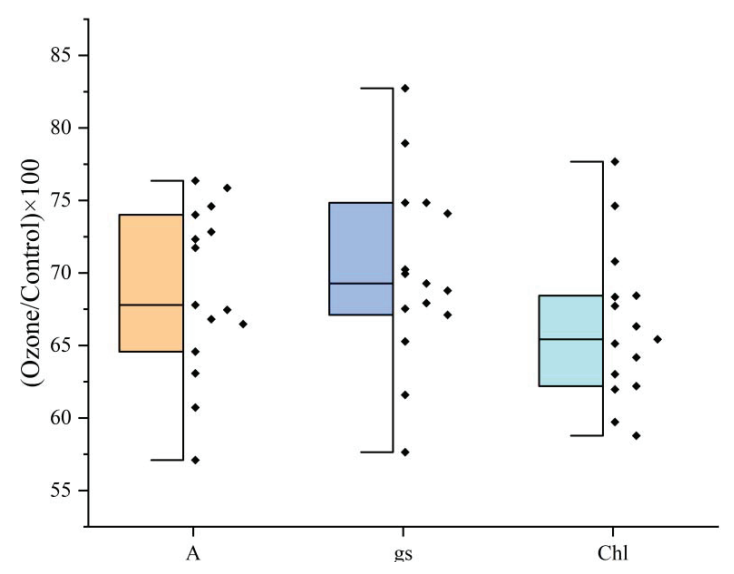

Figure 1. Relative physiological traits of 15 rice cultivars exposed to 100 ppb elevated ozone. ( $A=$ Photosynthetic rate, gs=Stomatal conductance, $\mathrm{Chl}=\mathrm{Chlorophyll}$ content)

$107|10-12| 2$ 


\section{Physiological traits}

Rice cultivars exposed to elevated ozone exhibited a significant reduction in photosynthetic rate, stomatal conductance and chlorophyll content. At elevated ozone treatment, the photosynthetic rate was significantly reduced maximally in MDU5 (Control: 24.44 and 03: $13.95 \mu \mathrm{mol} \mathrm{CO} \mathrm{m}^{2} \mathrm{~s}^{-1}$ ) and minimum reduction were observed in Anna(R)4 (Control: 26.10 and 03: $19.93 \mu \mathrm{mol} \mathrm{CO} \mathrm{m}^{-2}$ $\left.\mathrm{s}^{-1}\right)$. Similarly, ozone exposure caused a marked reduction in stomatal conductance were maximum in TRY(R)2 (Control: 0.48 and 03: $0.28 \mathrm{~mol} \mathrm{H}_{2} \mathrm{O} \mathrm{m}^{-2} \mathrm{~S}$ $\left.{ }^{1}\right)$ and minimum reduction in Anna(R)4 (Control:0.56 and $\left.\mathrm{O}_{3}: 0.46 \mathrm{molH}_{2} \mathrm{O} \mathrm{m}^{-2} \mathrm{~s}^{-1}\right)$. The maximum reduction in chlorophyll content were noticed in TRY(R)2 (Control: 34.93 and $0_{3}: 20.53$ ) and minimum in Anna(R)4 (Control: 37.93 and 03: 29.47) at 30 days of ozone exposure.

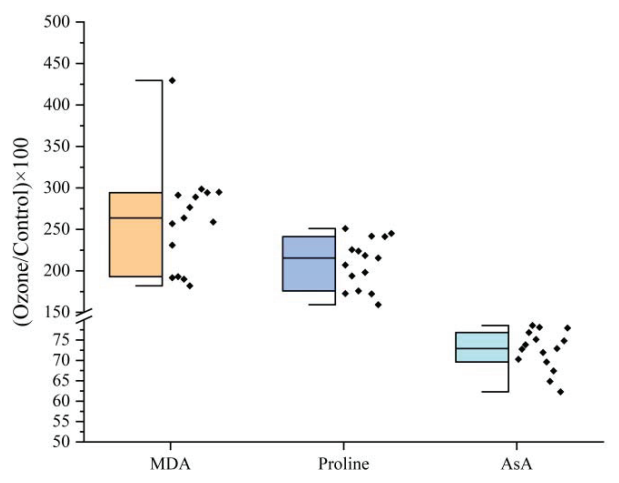

Figure 2. Relative biochemical traits of 15 rice cultivars exposed to 100 ppb elevated ozone. (MDA = Malondialdehyde content, Proline $=$ Proline content, AsA=Ascorbic acid content)

The relative physiological traits were varied among the photosynthetic rate, stomatal conductance and chlorophyll content. The boxplot of relative physiological traits of 15 rice cultivars are depicted in Figure 1. The maximum and minimum relative physiological traits were recorded 76.36 and $57.09 \%$ for photosynthetic rate, 82.73 and $57.63 \%$ for stomatal conductance and 77.68 and $58.77 \%$ for chlorophyll content. The results showed that the deviation between rice cultivars were less for photosynthetic rate and chlorophyll content compared to stomatal conductance. The mean values for relative plant traits were recorded as $67.79,69.27$ and $65.42 \%$ for photosynthetic rate, stomatal conductance and chlorophyll content, respectively. In terms of relative photosynthetic rate, stomatal conductance and chlorophyll content, 75 percentile of rice cultivars lies between 73.42 , 74.46 and $68.39 \%$, respectively and 25 percentile of rice cultivars located between 65.52, 67.31 and $62.60 \%$, respectively. These variations in relative plant traits were related to the genotypic difference among test rice cultivars. Furthermore, deviations in relative plant traits showed differences in tolerance levels of various rice cultivars under elevated ozone stress. The decrease in stomatal conductance was also observed by Chen et al. (2011) in rice genotypes of SL46 and NB under 5 days of ozone stress. Moreover, plants exposed to elevated ozone on a daily basis continuously decrease stomatal conductance, which negatively influences the photosynthetic rate (Fiscus et al. 2005). Similar to the current report, Akhtar et al. (2010) observed that $100 \mathrm{ppb}$ of ozone exposure significantly decreased the photosynthetic rate of BR11, BR14, BR28, and BR29 (Bangladeshi rice cultivars). Consistently decrease in chlorophyll content in the present study might be due to degeneration of chloroplast under elevated ozone stress, which ultimately alters the carbon assimilation capacity of the plant species (Jing et al., 2016).

\section{Biochemical traits}

Malondialdehyde and proline contents in all test rice cultivars showed significant increment under elevated ozone condition, whereas decrease in ascorbic acid content was noticed. The thirty days of ozone exposure increased MDA content maximally in Rice MDU6 (Control: 0.61 and $\mathrm{O}_{3}: 3.21 \mu \mathrm{mol} \mathrm{g} \mathrm{g}^{-1}$ FW) and least in PMK(R)3 (Control: 0.81 and $\mathrm{O}_{3}$ : $\left.1.47 \mu \mathrm{mol} \mathrm{g}{ }^{-1} \mathrm{FW}\right)$.

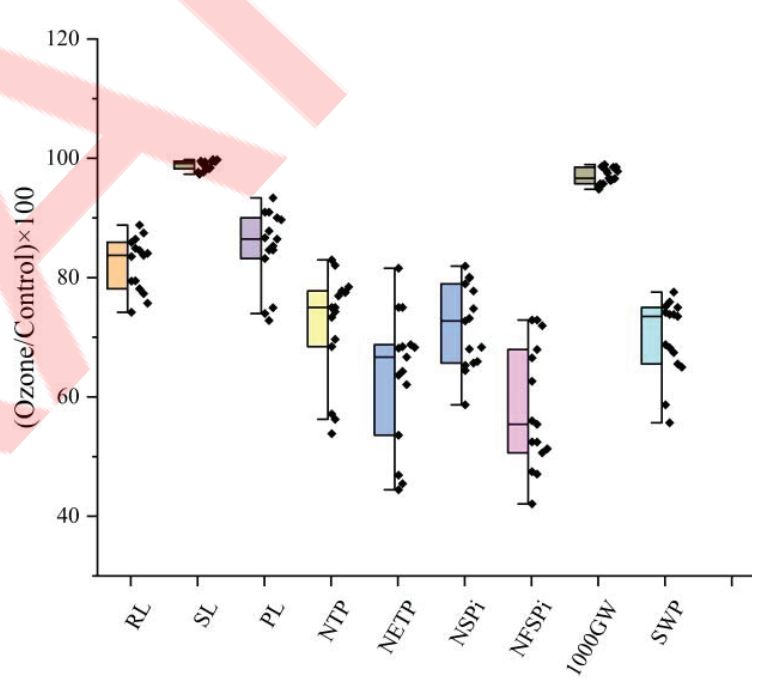

Figure 3. Relative growth and yield traits of $\mathbf{1 5}$ rice cultivars exposed to 100 ppb elevated ozone. (RL=Root length, SL=Shoot length, PL=Panicle length, NTP $=$ Number of tillers, NETP $=$ Number of effectivetillersper plant, $\mathrm{NSPi}=$ Number of spikelets per panicle, $\mathrm{NFSPi}=\mathrm{Number}$ of filled spikelets per panicle, $1000 \mathrm{GW}=$ Thousand grain weight, SWP=Straw weight)

The relative biochemical traits of 15 rice cultivars were depicted in Figure 2. The maximum and minimum relative biochemical traits were recorded 429.52 and $181.69 \%$ for photosynthetic rate, 
251.05 and $159.19 \%$ for stomatal conductance and 78.54 and $62.28 \%$ for chlorophyll content. The mean values for relative biochemical traits were higher for malondialdehyde (263.79\%) and proline content (215.49\%); whereas ascorbic acid content showed a less mean value of $72.89 \%$.

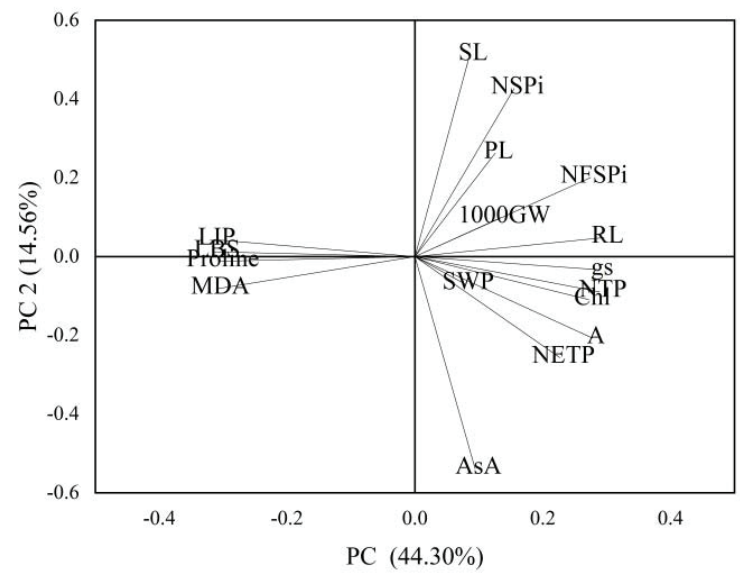

Figure 4. Principal component analysis describing plant traits of 15 rice cultivars exposed to $100 \mathrm{ppb}$ elevated ozone.

Higher in malondialdehyde and proline content were mainly due to a significant increase in malondialdehyde and proline content under elevated ozone exposure, while ascorbic acid content showed a decrease in the trend under elevated ozone stress. Moreover, in all biochemical traits, maximum number of rice cultivars were spread up to 75 percentile and the deviation was very higher for malondialdehyde and proline content compared to ascorbic acid content.

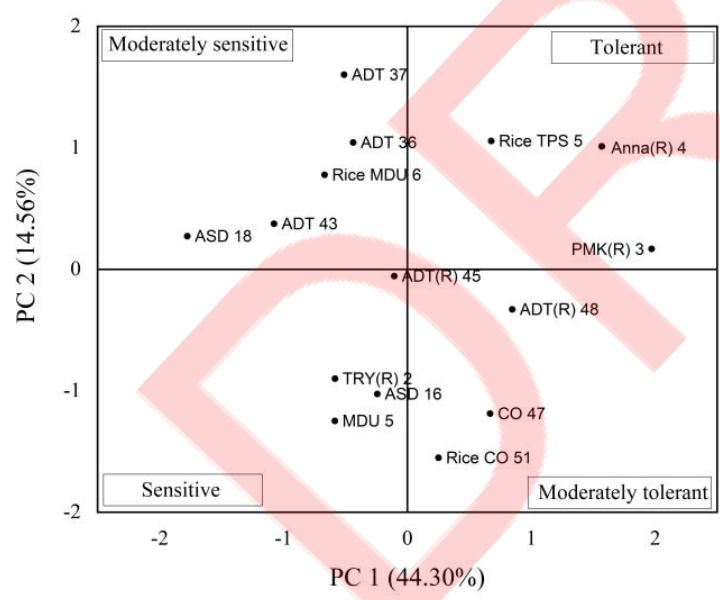

Figure 5. Principal component analysis describing classification of $\mathbf{1 5}$ rice cultivars exposed to $\mathbf{1 0 0}$ ppb elevated ozone.

An increase in malondialdehyde concentration under elevated ozone exposure in the present study was and this may be associated with an increase in lipid peroxidation and alterations in reactive oxygen species scavenging mechanism (Li et al., 2017).
Ozone accumulation under 100 ppb elevated ozone stress degenerated the ozone scavenging capacity of the leaves leads to an increase in malondialdehyde concentration and production of proline content in all test rice cultivars (Loreto, 2001). Similarly, Li et al. (2017) observed that MDA content increased in rice cultivars of Bt-SY63 and SY63 of about 30.6 and $23.7 \%$, respectively, in elevated ozone-treated plants. Furthermore, the production of proline in ozone-treated plants observed in the present study might be associated with the production of proline under abiotic stress conditions as an adaptive mechanism (Yang et al., 2012). Similarly, Upadhyaya et al. (2007) reported that a significant increase in proline content were observed in rice leaves exposed to 0.2 millimoles of hydrogen peroxide. Fumigation with $\mathrm{SO}_{2}, \mathrm{NH}_{3}$, and $\mathrm{NO}_{2}$ increased proline accumulation in rice cultivars of GR3 and TKM9 (Anbazhagan et al., 1988). Furthermore, a decrease in ascorbic acid content in rice leaves expose to elevated ozone is linked with poor non-enzymatic defense mechanism and AsA pool depleted gradually under continuous ozone exposure (Rai and Agrawal, 2008). Similarly, Frei et al. (2012) reported that rice ND6172 had decreased AsA contents by $20-30 \%$ compared to Nipponbare under 100 ppb ozone. Wang et al. (2013) observed that ozone sensitive rice cultivar Shanyou63 decreased AsA content by $22.75 \%$ than ozone tolerant Wuxiangjing14 exposed to elevated ozone (>250 nmol mol-1).

\section{Growth and yield traits}

The magnitude of decline in growth and yield traits i.e., root length, shoot length, number of tillers and 1000 grain weight were observed in all the rice cultivars due to elevated ozone exposure. The maximum reduction in tiller number were noticed in MDU5 (Control: 13.0 and $\mathrm{O}_{3}$ : 7.0) and showed minimum reduction for Anna(R)4 (Control: 15.7 and $\mathrm{O}_{3}$ : 13.0). The maximum reduction in 1000 grain weight was noticed in ASD16 (Control: 25.1 and $\mathrm{O}_{3}$ : $23.8 \mathrm{~g})$ while minimum reduction was observed in ADT43 (Control: 15.7 and $\mathrm{O}_{3}: 15.5 \mathrm{~g}$ ).

The relative growth and yield traits were described in Figure 3. The mean relative root, shoot and panicle length were recorded to be $83.74,99.13$ and $86.46 \%$, respectively. In terms of the number of tillers per plant, number of effective tillers per plant and number of spikelets per panicle were showed mean of $75.00,66.66$ and $72.73 \%$, respectively. In the current study, a decrease in root length, shoot length, panicle length and panicle number were attributed to a decrease in foliar carbon assimilation rate and it would have inhibited the growth and development of rice cultivars (Wang et al., 2013). Similarly, indica, japonica and bangladeshi rice cultivars also showed a decease in plant height and tiller number under elevated ozone treatment (Akhtar 
et al., 2010). Also, Shao et al. (2020) reported that the smaller panicle length was corresponded with a smaller plant and reduced tiller numbers which inhibited the effective tillers under ozone stress.

Similarly, the number of filled spikelets per panicle, 1000 grain weight and straw weight per plant were registered mean values of $55.42,96.65$ and $73.50 \%$, respectively. Among all growth and yield traits, most of the rice cultivars lie above 25 percentile for panicle length, the number of tillers per plant and number of effective tillers per plant. The deviation in relative plant traits was very high for number of effective tillers per plant and number of filled spikelets per panicle, whereas very low for shoot length and 1000 grain weight.

Table 1. Parentage and characteristics of 15 rice cultivars

\begin{tabular}{|c|c|c|}
\hline Rice cultivars & Parentage & Agronomic characteristics of cultivars \\
\hline ADT 36 & Triveni x IR 20 & Resistant to BPH and Blast \\
\hline ADT 37 & BG 280-12 x PTB 33 & Resistant to many pest and diseases \\
\hline ADT 43 & IR $50 \times$ White ponni & Resistant to Green Leaf Hopper \\
\hline ADT (R) 45 & IR $50 \times$ ADT 37 & Resistant to Gall midge \\
\hline ADT (R) 48 & IET 11412 x IR 64 & Resistant to Green Leaf Hopper, Stem borer and Gall midge \\
\hline Anna (R) 4 & Pantdhan 10 x IET 9911 & Drought tolerant \\
\hline ASD 16 & ADT 31 x CO 39 & Resistant to Blast \\
\hline ASD 18 & ADT $31 \times$ IR50 & Resistant to BPH \\
\hline CO 47 & IR $50 \times$ CO 43 & Resistant to Blast \\
\hline MDU 5 & O.glaberrima x Pokkali & Resistant to Drought \\
\hline PMK (R) 3 & UPLRI 7 x CO 43 & Drought tolerance \\
\hline Rice CO 51 & ADT 43 x RR $272-1745$ & $\begin{array}{l}\text { High yielding semi dwarf rice variety, } \\
\text { Moderately resistant to Brown Plant Hopper (BPH) and Green Leaf hopper }\end{array}$ \\
\hline Rice MDU 6 & MDU 5 x ACM 96136 & High yielding \\
\hline Rice TPS 5 & ASD16 x ADT37 & High yielding, Moderately resistant to stem borer and gall midge \\
\hline TRY (R) 2 & IET $6238 \times$ IR 36 & Saline/Alkaline tolerant \\
\hline
\end{tabular}

These deviations in plant relative traits were related to genotypic variations among the test rice cultivars. Furthermore, these results showing a difference in ozone tolerance level under elevated ozone stress. The decrease in yield traits ie., number of spikelets per panicle, number of filled spikelets per panicle and 1000 grain weight, were attributed to an alteration in assimilates allocation to panicles. This could be due to plant utilized more assimilates for their respiration and regulating antioxidant metabolism under elevated ozone stress. Similarly, elevated levels of ozone (100 ppb) decreased the spikelet number and filled spikelets per panicle in the Nipponbare rice variety (Wang et al., 2014). The decrease in filled spikelets per panicle and 1000 grain weight might be due to reduced fertilization efficiency of rice cultivars under ozone stress and it would affect the carbohydrate available for the grain filling process, which ultimately leads to reduction in grain yield (Jing et al., 2016). Similarly, ozoneinduced reduction in grain weight was observed in bangladeshi rice cultivars (Ashrafuzzaman et al., 2017), modern indica and japonica rice cultivars (Shao et al., 2020) under elevated ozone stress. Furthermore, reduction in straw weight was associated with decrease in photosynthetic rate, modification in phloem loading and translocation (Akhtar et al., 2010).

\section{Multivariate analysis}

Principal component analysis (PCA) was carried out to identify ozone tolerant and sensitive rice cultivars with respect to various plant traits under elevated ozone stress. PCA has been used to group the ozone tolerant and sensitive wheat cultivars (Fatima et al., 2019) and European beech (Löw et al., 2012). The first two principal components (PC1 and PC2) explained $44.30 \%$ and $14.56 \%$, respectively with the cumulative eigenvalue of $58.86 \%$. Most of the plant yield traits were clustered together and showed higher loading in first component, followed by physiological traits and biochemical traits showed lesser loading in the second component. These relative plant traits in two principal components representing the best descriptor for grouping rice cultivars (Figure 4). Further, Principle component categorized the 15 rice cultivars into four major groups indicating TRY(R) 2, ASD16, ADT(R)45 and 
MDU5 were ozone sensitive, ASD18, ADT43, Rice MDU6, ADT36 and ADT37 were moderately ozone sensitive, ADT(R)48 C047 and Rice C051 were moderately ozone tolerant and Rice TPS5, Anna(R)4 and $\mathrm{PMK}(\mathrm{R}) 3$ were ozone tolerant (Figure 5). Similarly, for accurate and reliable screening of salttolerant and sensitive rice cultivars ( 74 rice cultivars) Kakar et al. (2019) applied principal component analysis and Mazid et al. (2013) categorized 41 rice genotypes for screening of bacterial blight resistance genotypes using PCA.

\section{CONCLUSION}

The present investigation demonstrated the response of 15 rice cultivars in terms of physiological, biochemical, growth and yield traits to elevated ozone stress. The results indicated that all test rice cultivars significantly reduced the important plant traits, namely photosynthetic rate, stomatal conductance, chlorophyll content, tiller number, filled spikelets per panicle and 1000 grain weight. Moreover, studied plant traits clearly categorized the 15 rice cultivars into four different ozone sensitive (TRY(R) 2, ASD16, ADT(R)45 and MDU5), moderately ozone sensitive (ASD18, ADT43, Rice MDU6, ADT36 and ADT37), moderately ozone tolerant (ADT(R)48 C047 and Rice C051) and ozone tolerant (Rice TPS5, Anna(R)4 and PMK(R)3) groups. Hence, the present outcome would be useful for breeding ozone tolerant rice cultivars to overcome future climate change scenarios.

\section{FUNDING AND ACKNOWLEDGMENT}

The current research was financially supported by the Physical Research Laboratory (PRL), Indian Space Research Organization (ISRO), Ahmadabad, granted to Tamil Nadu Agricultural University (TNAU), Coimbatore, Tamil Nadu.

\section{Competing interests}

The authors declare that they have no known competingfinancialinterestsorpersonalrelationships that could have appeared to influence the work reported in this paper.

\section{REFERENCES}

Akhtar, N., Yamaguchi, M., Inada, H., Hoshino, D. Kondo, T., Fukami, M., Funada, R. and T. Izuta. 2010. Effects of Ozone on Growth, Yield and Leaf Gas Exchange Rates of Four Bangladeshi Cultivars of Rice (Oryza Sativa L.). Environ. Pollut., 158: 2970-2976.

Anbazhagan, M., Krishnamurthy, R. and K. A. Bhagwat. 1988. Proline: An Enigmatic Indicator of Air Pollution Tolerance in Rice Cultivars. J. Plant Physiol., 133: 122-123.

Ashrafuzzaman, M., Lubna, F. A., Holtkamp, W. J. F., Manning, T. K. and M. Frei. 2017. Diagnosing Ozone Stress and Differential Tolerance in Rice
(Oryza Sativa L.) With Ethylenediurea (EDU). Environ. Pollut., 230: 339-50.

Austin, J. and N. Butchart. 2003. Coupled chemistryclimate model simulations for the period 1980 to 2020: Ozone depletion and the start of ozone recovery. Q. J. R. Meteorol. Soc., 129: 3225-3249.

Avnery, S., Mauzerall, D.L. and A.M. Fiore. 2013. Increasing global agricultural production by reducing ozone damages via methane emission controls and ozone resistant cultivar selection. Glob. Change t Biol., 19: 1285-1299.

Biswas, D.K., Xu, H., Li, Y.G., Sun, J.Z., Wang, X.Z., Han, X.G. and G.M.J iang. 2008. Genotypic differences in leaf biochemical, physiological and growth responses to ozone in 20 winter wheat cultivars released over the past 60 years. Glob. Change Biol., 14: 46-59.

Chen, C. P., Michael, F. and M. Wissuwa. 2011. The OzT8 Locus in Rice Protects Leaf Carbon Assimilation Rate and Photosynthetic Capacity under Ozone Stress. Plant Cell Environ., 34:1141-49.

Daripa, A., Bhatia, A., Ojha, S., Tomer, R., Chattaraj, S., Singh, K.P. and S.D. Singh. 2016. Chemical and natural plant extract in ameliorating negative impact of tropospheric ozone on wheat crop: a case study in a part of semiarid north west india. Aerosol Air Qual Res., 16: 1742-1756.

Emberson, L.D., Büker, P., Ashmore, M.R., Mills, G., Jackson, L.S., Agrawal, M., Atikuzzaman, M.D., Cinderby, S.,Engardt, M., Jamir, C. and K. Kobayashi. 2009. A comparison of North American and Asian exposure-response data for ozone effects on crop yields. Atmos. Environ.. 43: 1945-1953.

Fatima, A., Singh, A. A., Mukherjee, A. Dolker, T., Agrawal, M. and S. B. Agrawal. 2019. Assessment of ozone sensitivity in three wheat cultivars using ethylenediurea. Plants. 8: 80.

Fiscus, E. L.., Booker, F. L. and K. O. Burkey. 2005. Crop Responses to Ozone: Uptake, Modes of Action, Carbon Assimilation and Partitioning. Plant Cell Environ., 28: 997-1011.

Frei, M., Wissuwa, M. Charles, P., Tanaka, J.P., Chen, K., Südekum, H. and Y. Kohno. 2012. Leaf Ascorbic Acid Level - Is It Really Important for Ozone Tolerance in Rice? Plant Physiol Biochem 59: 63-70.

Ghude, S.D., Jena, C., Chate, D.M., Beig, G., Pfister, G.G., Kumar, R. and V. Ramanathan. 2014. Reductions in India's crop yield due to ozone. Geophys. Res. Lett., 41: 5685-5691.

Hauglustaine, D.A., Lathiere, J., Szopa, S. and G.A. Folberth. 2005. Future tropospheric ozone simulated with a climate chemistry biosphere model. Geophys. Res. Lett., 32 : 1-5.

Jing, L., Dombinov, V., Shen, S., Wu, Y., Yang, L., Wang, Y. and M. Frei. 2016. Physiological and GenotypeSpecific Factors Associated with Grain Quality Changes in Rice Exposed to High Ozone. Environ. Pollut., 242-210: 397-408.

Kakar, N., Jumaa, S.H., Redoña, E.D., Warburton, M.L. 
and K.R. Reddy. 2019. Evaluating rice for salinity using pot-culture provides a systematic tolerance assessment at the seedling stage. Rice, 12: 12.

Kumari, S., Lakhani, A. and K.M. Kumari. 2020. First observation-based study on surface $\mathrm{O} 3$ trend in Indo- Gangetic Plain: Assessment of its impact on crop yield. Chemosphere, 255: 126972.

Lal, S., Venkataramani, S., Naja, M., Kuniyal, J.C., Mandal, T.K., Bhuyan, P.K., Kumari, K.M., Tripathi, S.N.,Sarkar, U., Das, T. and Y.V. Swamy. 2017. Loss of crop yields in India due to surface ozone: An estimation based on a network of observations. Environ. Sci. Pollut., 24: 20972-20981.

Li, C., Zhu, J., Zeng, Q., Luo, K., Liu, Liu, B. G. and H. Tang. 2017. Different Responses of Transgenic Bt Rice and Conventional Rice to Elevated Ozone Concentration. Environ. Sci. Pollut. 24: 83528362.

Loreto, F. 2001. Isoprene Produced by Leaves Protects the Photosynthetic Apparatus against Ozone Damage, Quenches Ozone Products, and Reduces Lipid Peroxidation of Cellular Membranes. Plant Physiol., 127: 1781-1787.

Löw, M., Deckmyn, G. de Beeck, M. O., Blumenröther, M. C., Obwald, W., Alexou, M., Jehnes, S., Haberer, K., Rennenberg, H., Herbinger, K., Häberle, K. H., Bahnweg, G., Hanke, D., Wieser, G., Ceulemans, R., Matyssek, R. and M. Tausz. 2012. Multivariate Analysis of Physiological Parameters Reveals a Consistent 03 Response Pattern in Leaves of Adult European Beech (Fagus Sylvatica). New Phytol., 196: 162-172.

Mauzerall, D.L. and X. Wang. 2001. Protecting agricultural crops from the effects of tropospheric ozone exposure:Reconciling science and standard setting in United States, Europe and Asia. Annu. Rev. Energy Environ., 26: 237-287.

Mazid, M.S., Rafii, M.Y., Hanafi, M.M., Rahim, H.A. and M.A. Latif. 2013. Genetic variation, heritability, divergence and biomass accumulation of rice genotypes resistant to bacterial blight revealed by quantitative traits and ISSR markers. Physiol. Plant., 149: 432-447

Mohan, S. and P. Saranya. 2019. Assessment of tropospheric ozone at an industrial site of Chennai megacity. J Air Waste Manag Assoc., 69: 10791095.

Prabakaran, P., Krishnasamy, V., Manikandan, A. and V. Rambabu. 2017. Consequence of meteorological factors on gaseous pollutants and seasonal erraticism in the ambient air of Chennai city. Am. J. Environ. Prot., 37: 461-474.

Pulikesi, M., Baskaralingam, P., Elango, D., Rayudu, V. N., Ramamurthi, V., and S. Sivanesan. 2006. Air quality monitoring in Chennai, India, in the summer of 2005. J. Hazard. Mater., 136: 589-596.

Rai, R., and M. Agrawal. 2008. Evaluation of Physiological and Biochemical Responses of Two Rice (Oryza Sativa L.) Cultivars to Ambient Air Pollution Using Open Top Chambers at a Rural Site in India. Sci. Total Environ., 407: 679-691.

Ramya, A., Dhevagi, P., Priyatharshini, S., Chandrasekhar,
C. N., Valliappan, K. and S. Venkataramani. 2020. Physiological and Biochemical Response of Rice Cultivars (Oryza Sativa L.) To Elevated Ozone. Ozone Sci. Eng., 1: 1-15.

Reddy, B. S. K., Kumar, K. R., Balakrishnaiah, G., Gopal, K. R., Reddy, R. R., Ahammed, Y. N., Narasimhulu, K, Reddy, S.S and S. Lal. 2010. Observational studies on the variations in surface ozone concentration at Anantapur in southern India. Atmos. Res., 98: 125-139.

Sarkar, A., Singh, A. A., Agrawal, S. B., Ahmad, A. and A. P. Rai. 2015. Cultivar Specific Variations in Antioxidative Defense System, Genome and Proteome of Two Tropical Rice Cultivars against Ambient and Elevated Ozone. Ecotoxicol. Environ. Saf., 115 :101-11.

Sarkar, A., Singh, A. A., Agrawal, S. B., Ahmad, A. and S.P. Rai. 2015. Cultivar specific variations in antioxidative defense system, genome and proteome of two tropical rice cultivars against ambient and elevated ozone. Ecotoxicol. Environ. Saf., 115: 101-111.

Shao, Z., Zhang, Y., Mu, H., Wang, Y., Wang, Y., and L. Yang. 2020. Ozone-induced reduction in rice yield is closely related to the response of spikelet density under ozone stress. Sci. Total Environ., 712: 13656.

Sharma, R. K., Chithambarathanu, T., and K. Elampari. 2013. Assessment of surface ozone levels in a semi- urban site and its predictions using neural network. Assessment, 3: 1527-1531.

Shi, G., Yang, L., Wang, Y., Kobayashi, K., Zhu, J., Tang, H., Pan, S., Chen, T., Liu, G. and Y. Wang. 2009. Impact of elevated ozone concentration on yield of four Chinese rice cultivars under fully open-air field conditions. Agric. Ecosyst. Environ., 131: 178-184.

Sinha, B., Singh Sangwan, K., Maurya, Y., Kumar, V., Sarkar, C., Chandra, B.P. and V. Sinha. 2015. Assessment of crop yield losses in Punjab and Haryana using 2 years of continuous in situ ozone measurements. Atmospheric Chem. Phys., 15: 9555-9576.

Sinha, B., Singh Sangwan, K., Maurya, Y., Kumar, V., Sarkar, C., Chandra, B. P. and V. Sinha, V. 2015. Assessment of crop yield losses in Punjab and Haryana using 2 years of continuous in situ ozone measurements. Atmospheric Chem. Phys., 15: 9555-9576.

Tai, A.P.; Martin, M.V.; Heald, C.L. 2014. Threat to future global food security from climate change and ozone air pollution. Nat. Clim. Chang., 4: 817.

Upadhyaya, H, Khan, M.H. and S.K. Panda. 2007. Hydrogen Peroxide Induces Oxidative Stress in Detached Leaves of Oryza Sativa L. Gen. Appl. Plant Physiol., 33: 83-95.

Van Dingenen, R., Dentener, F.J., Raes, F., Krol, M.C., Emberson, L. and J. Cofala. 2009. The global impact of ozone on agricultural crop yields under current and future air quality legislation. Atmos. Environ., 43: 604-618.

Wang, J., Zeng, Q., Zhu, J., Liu, G. and H. Tang. 2013. Dissimilarity of Ascorbate-Glutathione (Asa-gsh) 


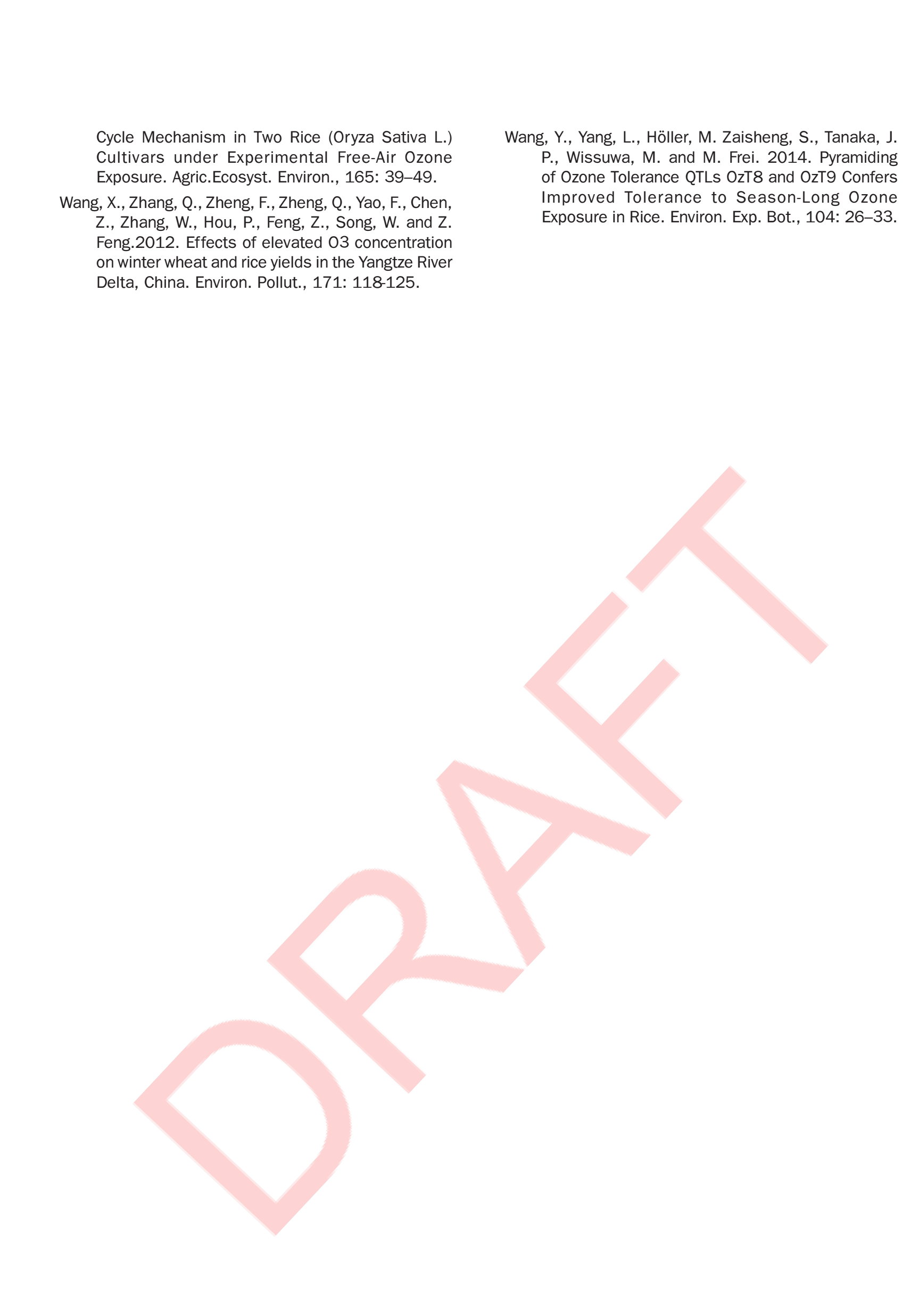

